\title{
Contributions of radioecology to the development of some modern concepts of ecotoxicology: From ecological half-life to monitored natural attenuation
}

\author{
I.L. Brisbin Jr., M.H. Smith and J.D. Peles \\ Savannah River Ecology Laboratory, P.O. Drawer E, Aiken, South Carolina 29803, U.S.A.
}

\begin{abstract}
Many of the modern concepts used in ecotoxicology have historical roots in earlier thinking from the field of radioecology. An example is the concept of Monitored Natural Attenuation (MNA), which is an approach to the remediation of contaminated waste sites, based on the natural degradation, sequestration or aging of toxic substances; contaminant inventory reduction proceeds in the absence of engineered treatment or removal activities. Because of potentially reduced costs compared to other altematives for waste site remediation, MNA has rapidly become a popular topic for research and development. Many years ago however, the field of radioecology recognized that biota and other ecosystem components contaminated with radioactive materials naturally decreased their contaminant burdens over time as the result of physical isotope decay and/or as the contaminants were sequestered or otherwise became unavailable for biological uptake. In the field of radioecology, this process is quantified as the ecological half-life (EHL), which is the time required for a population or other ecosystem component to reduce its contaminant burden by $50 \%$ after first coming into a steady-state with contaminant levels in other parts of its environment. Because of the ease with which they can be quantified in living organisms and environmental media, gamma-emining radionuclides have proved particularly useful for describing and quantifying EHLs in a variety of habitats. We summarize EHL studies based on more than 30 years of data for declines in ${ }^{137} \mathrm{Cs}$ levels in habitats at a forner nuclear weapons production facility in the southeastem United States. These studies of EHL are then related to the development of MNA programs for nonradioactive contaminants in these same or similar habitats. Of particular importance is the finding that EHL's car vary between habitat types for the same contaminant. Even within the same habitat, EHL's can vary spatially across microhabitats as well as between ecosystem components (e.g. in plants vs. animals) or even between species within a single trophic level/taxonomic group.
\end{abstract}

\section{INTRODUCTION}

Throughout the world, a legacy of nuclear and non-nuclear waste sites has forced many national governments to devise strategies and set priorities for the clean-up of these sites. Because of the costs involved in such clean-up, economic considerations have inevitably become an important part of the planning process. Frequently it has become necessary, on the basis of economic considerations alone, to limit engineered clean-up activities to only a few sites and leave others with no active treatment, allowing contaminant inventories to gradually decrease over time by the action of natural physical, biogeochemical, biological and/or ecological processes. Because of potentially reduced costs and the reduced amount of environmental disturbance involved, the latter approach has become an appealing option in many parts of the world. Known as "Monitored Natural Attenuation" (MNA), or "natural attenuation", this approach has become the subject of widespread research and conceptual development in recent years [1]. Many years ago however, radioecologists first described this same concept of natural contaminant attenuation over time and quantified it as the "ecological half-life" (EHL), which describes both the rate and pattern of the long-tern disappearance of radionuclides from contaminated habitats [3]. In this paper we describe past studies of EHL and indicate how their findings can both provide caveats to and direct the future development of conceptual thinking about the application of MNA.

\subsection{Monitored natural attentation}

Originally termed "natural attenuation," MNA was initially considered to be a "no action" approach and was applied only to cases of contamination with organic chemicals [2]. However it was quickly realized 
that as a knowledge-driven/science-based approach, MNA needed to include proactive approaches for monitoring rates and patterns at which contaminants were either being destroyed (e.g. biodegraded) or reduced in bioavailability. So far, MNA has been most frequently used in cases of groundwater and/or soil contamination, particularly at sites with chlorinated solvents, gasoline, polycylic aromatic hydrocarbons, pesticides, benzene and benzene derivatives. The most successful applications of MNA have been made in wetland habitats with soilsisediments high in organic matter (e.g. swamps and marshes). Sites for MNA application need to be particularly well characterized, to allow documentation of the extent to which natural remediation processes are occurring. To date, MNA approaches have not been identified with the clean-up of sites contaminated with radionuclides. However, as indicted below, some radioactively contaminated areas have shown significant decreases in their inventory of nuclear contaminants through the simple process of physical isotope decay.

\subsection{Ecological half-life}

The physical decay of radioactive contaminants provides a readily observable case of contaminant removal/destruction by natural non-engineered processes. Other factors however, both biological and ecological, may also act to accelerate or stabilize the rate of radioactive contaminant reduction and/or alter its bioavailability. All of these factors are quantified by the concept of ecological half-life (EHL). EHL (also referred to as "effective ecological half life" or simply "effective half life") may be defined as the amount of time required for a given level of contaminant, once established and at steady state within a given ecosystem component, to decease by $50 \%$ as a result of the isotope being either physically removed from or rendered biologically unavailable within the system [3]. In this definition, "physical removal" may include both actual passage of the contaminant out of the system (e.g. through downstream washing of sediments) or the physical decay of an isotope itself. Any case in which a calculated EHL exceeds the physical half-live of the isotope itself however, must involve continued isotope input into the ecosystem component under consideration. The concept of EHL must be distinguished from the more familiar concept of "biological half-life" (also called the physiological half-life) which quantifies the rate at which an organism eliminates an isotope from its body [3]. Unlike EHL, biological half-lives are determined by the physiological characteristics of the organisms in which they are measured. Thus for example, the biological half-life of ${ }^{137} \mathrm{Cs}$ in a poikilothermic vertebrate such as a snake may be as long as 900 days while that of a duck, with a much higher metabolic rate, could be as little as 5-6 days [3]. However when snakes and ducks live in steady state with ${ }^{137} \mathrm{Cs}$ in the same swamp ecosystem, their ecological half-lives are more similar (3.8 vs. 1.9 years respectively). This is a consequence of their EHL's being determined by the characteristics of the swamp ecosystem rather than by their own physiological characteristics [3].

\section{SOME CASE STUDIES - LESSONS LEARNED}

For more than three decades, studies of the distribution of ${ }^{137} \mathrm{Cs}$ have been conducted in contaminated natural habitats on the U.S. Department of Energy's $750 \mathrm{~km}^{2}$ Savannah River Site in west-central South Carolina, USA. Following its release from the site's nuclear industrial facilities from the 1950's through the mid-1980's, this long-lived gamma-emitting radioisotope has shown long-term changes in bioavailability and distribution in the site's flora, fauna and other ecosystem components (soil, sediments, water). These data provide a unique opportunity to quantify the rate and pattern of this contaminant's decline in these ecosystem components and thus estimate EHL. We now summarize the published results of some of these studies and provide some new interpretations. Finally, we then consider these data and their analyses as the basis for a better understanding of some of the limitations that should be applied to any attempt to institute MNA programs in these or similar ecological situations.

\subsection{Published studies}

Most of the studies of the EHL of ${ }^{137} \mathrm{Cs}$ on the SRS have focused on mobile species of fish or wildlife which could concentrate this contaminant in their edible skeletal muscle tissue and then be harvested and 
consumed by members of the hunting/fishing public $[4,5,6]$. Most of these studies have dealt with one or two aquatic habitats on the SRS: (1) the contaminated floodplain of Steel Creek, a former reactor effluent stream and the riverine swamp into which it empties, and (2) former reactor cooling reservoirs which were inadvertently contaminated as a result of site operations. Further details concerning the contamination history and ecological characteristics of these lotic (stream/swamp) and lentic (reservoir) habitats have been provided elsewhere [3, and references therein].

\subsubsection{EHL's in lotic vs. lentic systems}

It's not surprising that the EHL's of fish and wildlife residing in lotic (stream) ecosystems are shorter than those in similar lentic (reservoir) habitats on the SRS $[3,4,5,6]$. As a result of the more rapid downstream movement of water and sediments in the lotic ecosystems, contaminated material is removed more rapidly and/or, in the case of sediments, may also have become less bioavailable as a result of being covered by less contaminated sediments from farther upstream. Surprisingly though, these differences in EHL were detectable and could even be quantified in migratory waterfowl such as American coots (Fulica americana) which only spend the winter months on these SRS wetlands. Thus, for example, EHL's of ${ }^{137} \mathrm{Cs}$ 'averaged 4.3 years in these coots on a reactor cooling reservoir [6], while the EHL of this same isotope was only half that amount (1.9 years [3]) in year-round resident wood ducks (Aix sponsa) inhabiting the lotic Steel Creek watershed. This difference in EHL's persisted despite the fact that the migratory coots left the SRS each spring to travel to more northerly breeding grounds where they annually purged themselves of their ${ }^{137} \mathrm{Cs}$ body burdens and then reacquired steady state contamination levels upon their return to the SRS the following fall.

\subsubsection{Microhabitat differences in EHL}

Even within a single reservoir, the extremely high site faithfulness of coots returning year after year to the same cove and even to the same portion of reservoir shoreline within that cove, resulted in these birds displaying different EHL's in different specific locations of that reservoir [6]. Moreover, differences in these regionally specific EHL's within the same reservoir could be explained by the differing histories of inputs of contaminated reactor effluents to these respective microhabitats. Thus EHL's can be potentially sensitive long-term indicators of environmental contamination histories - even when measured in wideranging birds such as migratory coots. This is even true where the differences of contaminant input histories vary over only restricted geographic scales - in the case of the one SRS reservoir for example, by as little as 1-2 km [6]. EHL's of fish (Lepomis sp.) collected from locations $\pm 5 \mathrm{~km}$ apart in Steel Creek similarly differed by more than twofold ( 3.29 vs. 7.00 years [4]) thus indicating that microhabitat differences in EHL can occur in lotic as well as lentic ecosystems

\subsubsection{Differences in EHL between species/trophic levels with in ecosystems}

EHL is based on the premise that all flora, fauna and other ecosystem components generally maintain a short-term dynamic steady state with regard to contaminant concentrations over time. It would therefore be expected that ideally, as contaminant levels decline in one or more of these components, levels in all other components should decline with the same general pattem and at the same general rate. In the real world, however, contaminant levels in various ecosystem components are seldom in a perfect steady state and data now indicate that important differences can exist in both the pattern and rate of contaminant decline/attenuation, even between closely related species within the same ecosystem. These differences can have important implications for both the application of MNA and the prediction of its effectiveness in such ecosystems.

Of particular importance is the suggestion that within the SRS' Steel Creek floodplain, ${ }^{137} \mathrm{Cs}$ levels in terrestrial vegetation are apparently declining at a slower rate than in consumer organisms associated with this vegetation. This conclusion is emerging from the comparison of ${ }^{137} \mathrm{Cs}$ levels that have been 
determined for a variety of flora and fauna from these habitats over the past 30 years. The results of these comparisons have been summarized by Peles et al. [7] who add their own data for EHL's of various plant species from this same location. These authors suggest that the covering of more contaminated sediments by cleaner sediments washed down from farther upstream may have reduced the amount of ${ }^{137} \mathrm{Cs}$ contamination that the consumers were acquiring from the incidental ingestion of soil or sediment particles. Rooted vegetation, however, still maintaining direct contact with the deeper more contaminated sediments, did not decline in ${ }^{137} \mathrm{Cs}$ contamination as rapidly as the consumers. Whether or not this explanation subsequently proves to be true, the fact that rooted vegetation and consumer organisms associated with it can decline in contaminant levels at different rates over extended periods of time is certainly worth noting.

Even within the consumer group moreover, studies of snakes [8] have shown that two species, both acting as top-level carnivores in the same ecosystem, while declining in contaminant concentration at similar rates, can do so with significantly different patterns of decline (linear vs. non-linear). Again, the implications of such findings for the effectiveness of MNA to deal with the contamination of any particular species, perhaps one consumed by the hunting/fishing public, should be obvious.

\section{IMPLICATIONS OF EHL STUDIES FOR MNA PROGRAMS}

The factors that determine EHL's for a radionuclide like ${ }^{137} \mathrm{Cs}$ in a given organism or population should affect other forms of environmental contaminants (e.g. organics or heavy metals) in the tissues of that same organism or population in largely the same way. This should be true regardless of the chemical characteristics and/or physiological reactions of that contaminant. Thus for example, ecological factors that would repel vs. attract migratory waterfowl to a contaminated wetland would affect the input vs. removal of organic, heavy metal or radionuclide contaminants incorporated into these birds' bodies in the same way. Similarly, in the Steel Creek reactor effluent stream on the SRS, increasing the rate at which contaminated sediments are being covered with uncontaminated sediments from further upstream would generally decrease the bioavailability of those contaminants to resident consumer organisms in roughly the same way.

Although there are exceptions to the above, there are good reasons to believe that lessons learned from EHL studies such as those of ${ }^{137} \mathrm{Cs}$ on the SRS, should be useful for MNA programs aimed at other forms of environmental contaminants in these same or similar ecosystems. These considerations would be of particular importance for the development and application of a new generation of biota-oriented MNA programs which would expand on those of the past which have dealt almost exclusively with non-biotic media such as soil, sediments or water. To now extend MNA programs to the biota of the same ecosystem(s) will unavoidably introduce a higher degree of variability, complexity and uncertainty to all contaminant cycling rates and patterns being monitored. For example, species which show significant annual cycles of variation in contaminant levels (e.g. ${ }^{137} \mathrm{Cs}$ in wintering coots on Par Pond [3]) place special constraints on the months when such species must be sampled in succeeding years (i.e. always in the same month). Only in this way can their EHL be conrectly estimated and proper conclusions drawn for MNA program applications. In such cases the special insights that can now be provided by past radioecological studies of EHL's offer an as yet untapped source of understanding of how such biotic variability can be both predicted and managed as part of future MNA program efforts.

\section{Acknowledgements}

We are grateful to Carl Strojan and Paul Bertsch for helpful comments on an earlier version of this manuscript. Studies at the SRS and manuscript preparation were supported by Financial Assistance Award Number DE-FC09-96SR1856 from the U.S. Department of Energy to the University of Georgia Research Foundation. 


\section{References}

[1] U.S. Environmental Protection Agency, A Citizen's Guide to Natural Attenuation, U.S. Env. Protection Agency Technology Fact Sheet EPA-542-F-96-015, (Nat. Center for Env. Publ. and Information, Cincinnati, OH, 1996).

[2] U.S. National Academy of Sciences, Natural Attenuation for Groundwater Remediation, (Nat. Acad. Press, Washington, D.C. 2000).

[3] I.L. Brisbin, Jr, Current Ornithology, 8 (1991) 69-140.

[4] M.H. Paller, J.W. Littrell, E.L. Peters, Health Physics 77 (1999) $392-402$.

[5] J.D. Peles, A.L. Bryan, C.T. Garten Jr., D.O. Ribble, M.H. Smith, Sci. Total Env. 263 (2000) 255-262.

[6) I.L. Brisbin, Jr., R.A. Kennamer, Studies in Avian Biol. 21 (2000) 57-64.

[7] J.D. Peles, M.H. Smith, I.L. Brisbin, Jr., Jour. Env. Radioactivity (in press).

[8] C. Bagshaw, I.L. Brisbin, Jr., J. Appl. Ecol. 21 (1984) 407-413. 